\title{
Development of an IoT-Driven System for High Valued Crop Farming
}

\author{
Domingo Junior P. Ngipol, Thelma D. Palaoag
}

\begin{abstract}
The use of technology in agriculture plays a vital role in revolutionizing traditional methods of farming. The insufficiency of technology and the use of traditional methods of farming results to low yielding of crops. The integration of smart agriculture using Internet of Things is an absolute solution in modernizing the traditional methods of farming. This paper aims to design and develop an IoT-driven system for high valued crop farming which automates farming processes like watering, distribution and application of fertilizer. It provides real-time monitoring and collection of information about the farm conditions like moisture, temperature, fertility of soil and level of water. Qualitative and quantitative data were gathered by means of interview and survey questionnaires which were given to Alfonso Lista, Ifugao farmers and Yaojiaxi Corporation personnel. The majority of the respondents evaluated the functionality of the system as "Fully Functional", usability as "Very Usable", efficiency as "Mostly Efficient" and maintainability as "Mostly Agree" based from the result of ISO standard criteria survey questionnaires. The developed prototype realized smart farming which promotes sustainable agriculture involving the integration of IoT technology into existing farming practices that definitely reduces manual work, man power and provides efficiency on the use of farming resources.
\end{abstract}

Keywords: Internet of Things, Smart Agriculture, High Valued Crop Farming.

\section{INTRODUCTION}

The economic development of a country mostly depends on agricultural products as it is the primary source of food and other crude supplies. It provides employment opportunities, income and domestic product to the people. The Philippine labor force in 2017 with 42.78 million people has engaged in the agriculture business with 10.26 million people in it, signifying a 25.44 percent of the national work force [1]. However, the use of traditional methods of farming greatly affects farmers which results in low yielding of crops. It is evident that the automation of manual processes of farming and the use of automatic machineries improved the yielding of crops [2]. Improving farm productivity is essential in order to increase farm productivity and to provide the fast rising demand of food caused by fast population growth all over the world.

According to the United Nations' Food and Agriculture Organization, agricultural product must be intensified by 50 percent in order to provide food for the fast rising number of people that is likely to reach 10 billion by 2050 . The urgent

need in increasing the crop efficiency is vital as it is the foundation of various solution for food scarcity and farm

Revised Manuscript Received on January 2, 2020.

* Correspondence Author

Domingo Junior P. Ngipol* , College of Computing Sciences, Ifugao State University, Ifugao Province, Philippines. Email: ngipoldj@gmail.com

Thelma D. Palaoag, College of Info. Tech. and Com. Science, University of the Cordilleras, Baguio, Philippines. Email: tpalaoag@gmail.com productivity problems [3]. The sustainability in agriculture plays an important role in addressing this challenges since it offers technological advancement that increase productivity and profitability while conserving resources, minimizing waste and environmental impact, and promoting agroecosystem resilience [4].

Hence there is a need to integrate smart agriculture using Internet of Things (IoT) technology in order to achieve sustainable agriculture with increase productivity, profitability and the worth of farming yields [5]. Non-traditional food yields in the Philippines such as vegetables, fruits, flowers, condiments and spices are considered as high value crops. These high valued crops are likely to have greater market cost as compared to the customary cereal grains and traded produces. High value crops are mostly grownup for business in either domestic and international markets and are not often part of the regular food of the local people.

Over the past few years, IoT technology has been introduced in nearly every single part of the current society. Amongst these areas are Smart Cities, Smart Health Care, Smart Industry, Autonomous Vehicle, Smart Agriculture, Precision Agriculture and others [6]. Internet of Things is acknowledged as one of the greatest significant parts of the future technology which gains attention from various companies and industries like Google, Apple, Samsung and Cisco [7]. The IoT is referred to as the Internet of Objects that integrates numerous technologies such as computers, the internet, network sensors, wireless communication technology and embedded systems to create a system that is capable of data transmission without human intervention [8] As a developing model, the IoT has boundless prospective that can devise an important influence on the future of the world [9].

The application and use of the modern IoT technologies in the farming practice allows customary ways of farming to be changed necessarily on every single aspect, paving way to a new agriculture pattern of precision agriculture [10]. Iot devices such as wireless sensor networks, network-connected weather stations, cameras, and smart phones are capable of gathering huge total of environmental and yield performance data reaching from time sequence data from sensors, to three-dimensional data from cameras and to human observations. This data are examined to filter out invalid data and compute personalized crop recommendations for any specific farm [11]. IoT technologies such as IoT devices provides a better way of collecting, gathering, exchanging, and transmitting data which absolutely delivers an innovative means in data handling and smart decision-making [12]. 
The Internet of Things provides the fundamental network infrastructure to the physical and the digital worlds through which smart things, ranging from micro sensors to heavy agricultural vehicles communicate to each other [13]. It is capable of transforming the agricultural domain into more efficient and productive farming and improves the quality of life of farm personnel by decreasing heavy labor and tiresome farm duties [14]. At present, a huge quantity of smart objects and diverse kinds of devices are unified and interconnect by means of the internet protocol. With an upsurge in the setting out of smart objects, the internet of things ought to devise an important influence on human life in the near future [15].

Smart agriculture includes the use of the Internet of Things (IoT) to provide solutions via the automatic monitoring of crops, as well as related farm conditions [16]. Successful farm output needs crop performance to be monitored and anticipated in an extensive variability of environmental, soil, fertilization, and irrigation conditions [17]. Moreover, Iot-based smart farming allows farmers to have enhanced control over the course of growing crops and making it more predictable and easy to manage [18]. Consequently, the absolute integration of IoT technologies into smart farming advanced the agriculture to a new level by which the whole agriculture industry is modernized with increased productivity and profit. In a broader perspective, the scope of smart agriculture which covers IoT improves or solves critical issues such as drought response, crop yield optimization, land and water management, and pest control [19].

In this regard, the research aims to determine the agricultural status, existing crops farming technology and infrastructure for high valued crops in Alfonso Lista, Ifugao. It also draws the features considered in the development of the IoT-driven system for high valued crops farming. The level of acceptability of the developed system is evaluated using the ISO 9126 standard as to its functionality, usability, efficiency and maintainability to address added features necessary in the development of the system.

\section{METHODOLOGY}

The study has been designed and developed through quantitative and qualitative research methods. The data collection method was primarily made through in-depth interviews and survey questionnaires with Alfonso Lista, Ifugao farmers, the farm manager and farm workers of the Yaojiaxi Corporation - Alfonso Lista.

The implementation of the IoT-Driven System for high valued crops farming is continued through a tough choice of indispensable IoT Technology framework as shown in Fig. 1 which encompasses the end-device, edge-device and server and backend. The end-device includes actuators and sensors, Embedded IoT platforms, wireless technologies and power sources which primarily aim to acquire and collect data from the physical world.

The edge-device includes network technologies such Wi-Fi, Bluetooth and $3 \mathrm{G}$ which serves as gateway that provides data routing and addressing paths for network communication. The server and backend includes the mobile application and the monitor that constitute the front end of the whole IoT framework which provides personalized based services according to user relevant needs.

The system evaluation was based from the ISO 9126 standard which was utilized as an effective tool for evaluating the level to which the system can be used by identified users to accomplish measured purposes with functionality, usability, efficiency and maintainability in a measured background of usage. The features of ISO 9126 standard survey are moderately fast and stress-free for the respondents to complete and for the researchers to give points, advantageous and can be scored instantaneously after completion. It is composed of eleven statements having a five-point scale each that ranges from one (1) as Strongly Disagree to five (5) as Strongly Agree.

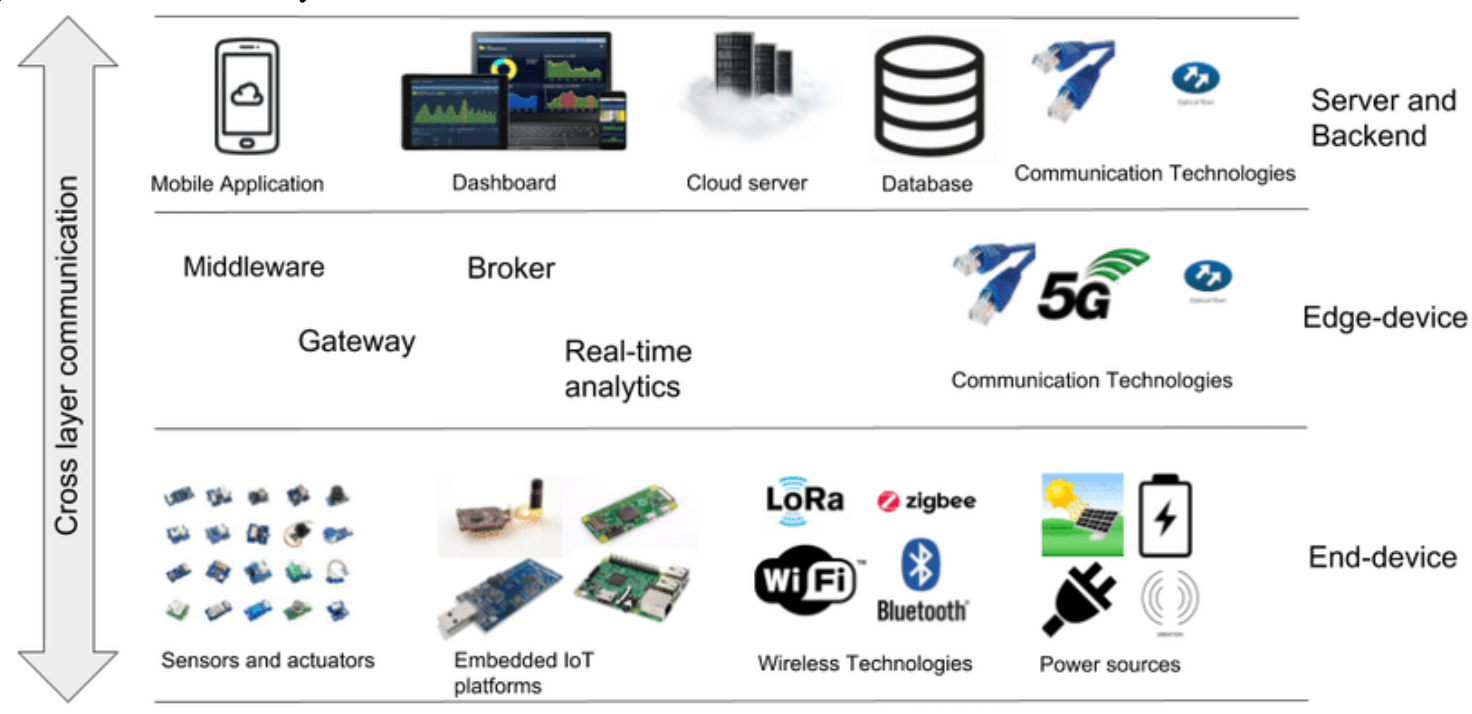

Fig. 1. The Internet of Things Framework.

\section{FINDINGS}

Agricultural crop farming in Alfonso Lista, Ifugao were using traditional methods of farming which greatly affects the productivity of the Ifugao farmers. Farm machineries such as tractors and harvesters are readily available during the preparation of soil for planting and the cultivation of soil after planting.

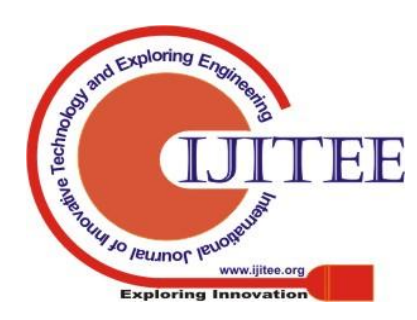


However, crops watering and fertilizer distribution and application are done manually which causes water scarcity or wastage and fertilizer misuse. The lack of crop monitoring and soil testing results to misuse of fertilizers which in turn causes soil quality degradation and hinders bountiful yield.

Numerous features were reflected in the development of the IoT-driven system for high valued crops farming based from the existing crops farming technology and infrastructure in Alfonso Lista, Ifugao which aims to revolutionize farming method of the Ifugao farmers. As such, the researchers used microcontrollers, sensors and actuators to automatically facilitate farming processes such as watering, fertilizer distribution and application, real-time monitoring and analysis on farm circumstances like weather, moisture, temperature, humidity, fertility of soil and level of water. Fig. 2 shows the IoT-Driven system block diagram.

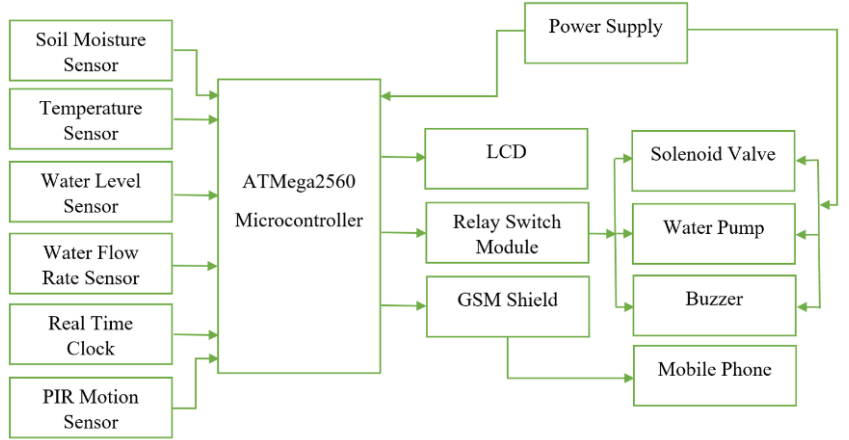

Fig. 2. System Block Diagram.

The IoT-driven system provides useful services to the farmer which allows them to easily manage their farm with automatic crop monitoring, watering, distribution and application of fertilizers. The system reduces manual work and man power which in turn decreases farming expenditures. It allows an automatic notification to the farmer regarding the level of water and fertilizer which anticipates the need to refill the water and fertilizer tanks. It also automatically notifies the farmer whenever there are burglars and destructive animals around the farm. The system efficiently uses farm resources such as water, fertilizers and chemicals which absolutely prevents environmental hazards.

The overall IoT system infrastructure that enables the connection of all components into a robust system is presented in the Fig. 3. In this context, the microcontroller governs the entire task for the whole system. It is powered by a rechargeable battery that is being recharge by a solar panel. Basically, a drip irrigation system is used to facilitate the watering, distribution and application of fertilizers with the automatic control of various sensors like the water level sensor which enables the water pump to turn on or off whenever it reaches the water level threshold value, the solenoid water valve which open or close whenever it triggers by the real-time clock and the soil moisture sensor.

The sensors such as the soil moisture sensor, temperature sensor, water level sensor, passive infrared (PIR) sensor and the water flow rate sensor were utilized to obtain and collect data from the IoT environment which is processed and serves as a basis for the actuators (example: water pump, solenoid valve, buzzer and GSM shield) to operate. As a mode of interconnecting the electronic component of the system, various network technologies such as $3 \mathrm{G}$, Bluetooth and Wi-Fi was utilized to address distance constraints. Monitor such as LCD and smartphone were used for user notifications and graphical representations.

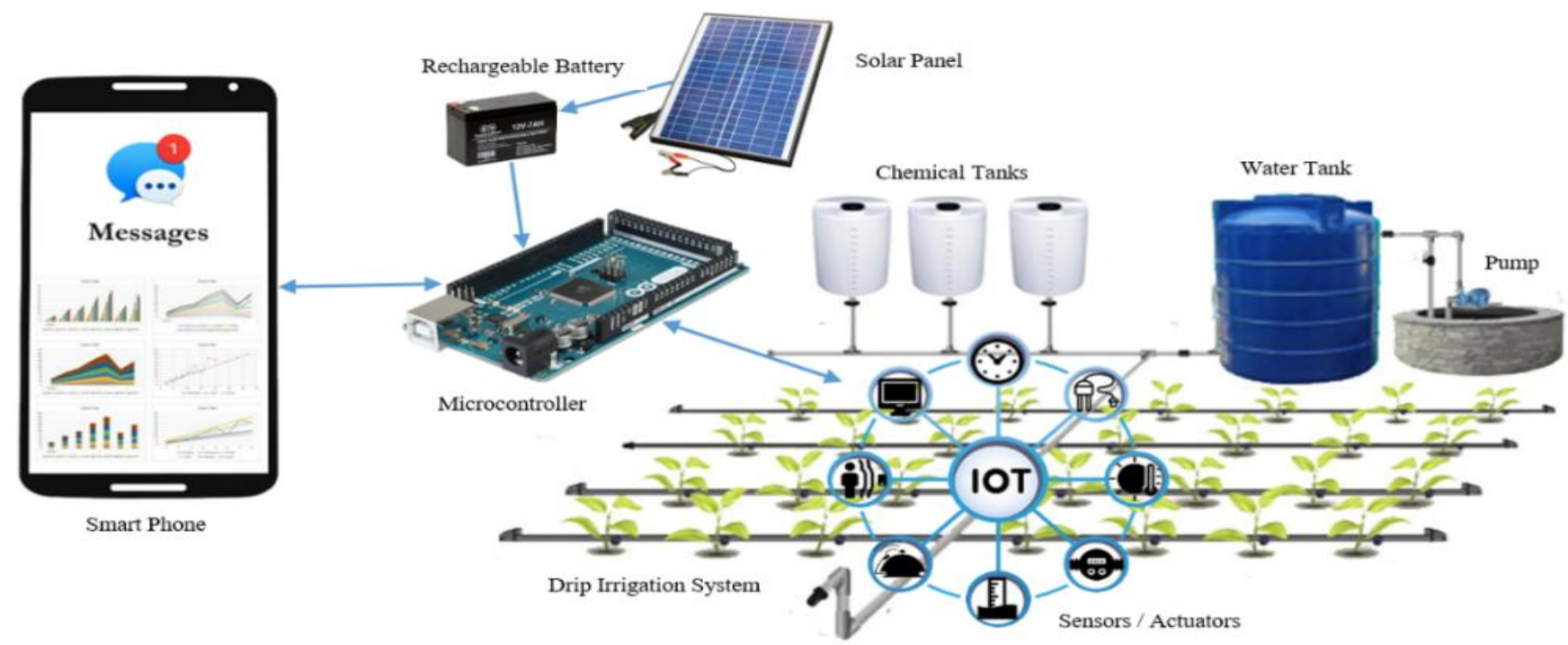

Fig. 3. IoT System Infrastructure

The IoT-driven system is suitable for high valued vegetables in the Philippines such as potato, string beans, sweet peas, cabbage, pechay, broccoli, hot pepper, bell pepper, sweet pepper, garlic, onions and fruit bearing plants such as dragon fruit and other crops were the IoT-driven system is applicable. Fig. 4 shows the IoT-driven system prototype. 


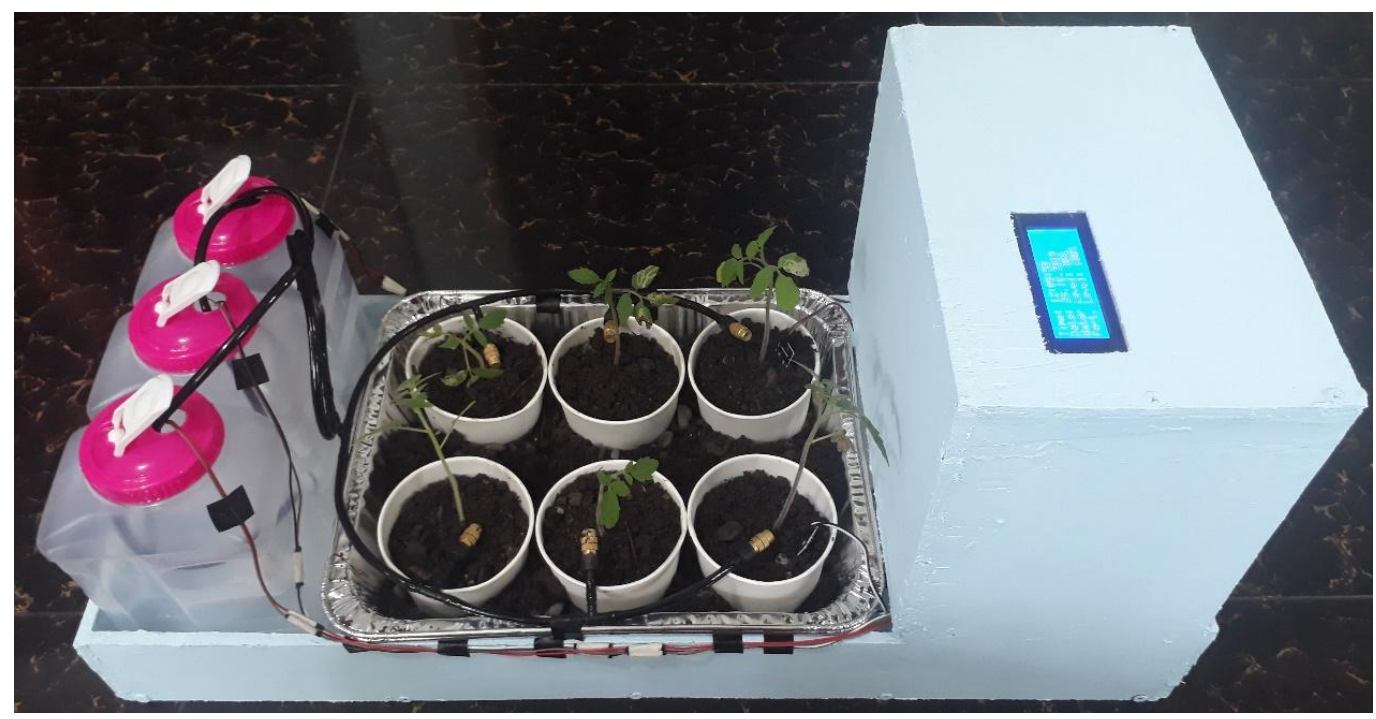

Fig. 4. IoT-Driven System Prototype

A total of forty (40) farm workers from the Yaojiaxi Corporation and Ifugao farmers served as respondents of the study. The scale below was used as an indicator to determine the qualitative description.

Table- I (a): Qualitative Description per Functionality Indicator [20]

\begin{tabular}{|c|c|}
\hline Limits of Scale & Quality Description \\
\hline $4.21-5.0$ & Fully Functional \\
\hline $3.21-4.20$ & Mostly Functional \\
\hline $2.61-3.20$ & Functional \\
\hline $1.81-2.60$ & Slightly Functional \\
\hline $1.0-1.8$ & Not Functional \\
\hline
\end{tabular}

Table- I (b): Functionality Indicators.

\begin{tabular}{|l|c|c|c|}
\hline \multicolumn{1}{|c|}{ Questions } & N & Mean & Interpretation \\
\hline $\begin{array}{l}\text { 1. The system performs the assigned } \\
\text { task correctly }\end{array}$ & 40 & 4.5 & $\begin{array}{c}\text { Fully } \\
\text { Functional }\end{array}$ \\
\hline $\begin{array}{l}\text { 2. The system provides the expected } \\
\text { results }\end{array}$ & 40 & 4.2 & $\begin{array}{c}\text { Mostly } \\
\text { Functional }\end{array}$ \\
\hline $\begin{array}{l}\text { 3. The system meets the user's } \\
\text { existing requirements }\end{array}$ & 40 & 4.3 & $\begin{array}{c}\text { Fully } \\
\text { Functional }\end{array}$ \\
\hline \multicolumn{1}{|c|}{ OVERALL MEAN } & & 4.33 & $\begin{array}{c}\text { Fully } \\
\text { Functional }\end{array}$ \\
\hline
\end{tabular}

Table I (b) shows that all of the evaluation criteria has an overall mean of 4.33 which implies that the developed prototype as rated by the respondents is Fully Functional and conforms with the functionality projected by the respondents. According to M. Salleh et al. [21], functionality is the ability of the software to deliver functions that complies or conforms to a given condition based on the functional requirements as a result in the table. Therefore, the system complies with the requirements of ISO 9126 as far as functionality is concern.

Table- II (a): Qualitative Description per Usability Indicator

\begin{tabular}{|c|c|}
\hline Limits of Scale & Quality Description \\
\hline $4.21-5.0$ & Very Usable \\
\hline $3.21-4.20$ & Mostly Usable \\
\hline $2.61-3.20$ & Usable \\
\hline $1.81-2.60$ & Almost Usable \\
\hline $1.0-1.8$ & Not Usable \\
\hline
\end{tabular}

Table- II (b): Usability Indicators

\begin{tabular}{|l|c|c|c|}
\hline \multicolumn{1}{|c|}{ Questions } & N & Mean & Interpretation \\
\hline $\begin{array}{l}\text { 1. It is easy for the users to } \\
\text { comprehend the logical concept and } \\
\text { applicability of the system }\end{array}$ & 40 & 4.4 & Very Usable \\
\hline 2. The system is easily learned & 40 & 4.6 & Very Usable \\
\hline $\begin{array}{l}\text { 3. The system is operated with } \\
\text { minimal effort }\end{array}$ & 40 & 4.2 & Mostly Usable \\
\hline \multicolumn{1}{|c|}{ OVERALL MEAN } & & $\mathbf{4 . 4 0}$ & Very Usable \\
\hline
\end{tabular}

Table II (b) shows the system's usability with an overall mean of 4.40 which imply that the developed prototype as rated by the respondents is Very Usable and offers the ease of use for a given function of the system. As stated in the ISO 9162 standard, usability is the ability of the system to be understood, learned, used and eye-catching to the user, when used under identified circumstances.

Table- III (a): Qualitative Description per Efficiency Indicator

\begin{tabular}{|c|c|}
\hline Limits of Scale & Quality Description \\
\hline $4.21-5.0$ & Very Efficient \\
\hline $3.21-4.20$ & Mostly Efficient \\
\hline $2.61-3.20$ & Efficient \\
\hline $1.81-2.60$ & Almost Efficient \\
\hline $1.0-1.8$ & Not Efficient \\
\hline
\end{tabular}

Table- III (b): Efficiency Indicators

\begin{tabular}{|l|c|c|c|}
\hline \multicolumn{1}{|c|}{ Questions } & N & Mean & Interpretation \\
\hline $\begin{array}{l}\text { 1. The system respond in a timely } \\
\text { manner }\end{array}$ & 40 & 4 & Mostly Efficient \\
\hline $\begin{array}{l}\text { 2. The system utilize resources } \\
\text { efficiently }\end{array}$ & 40 & 4 & Mostly Efficient \\
\hline \multicolumn{1}{|c|}{ OVERALL MEAN } & & $\mathbf{4 . 0 0}$ & Mostly Efficient \\
\hline
\end{tabular}

Table III (b) shows the system's efficiency with overall mean of 4.00 which implies that the developed prototype as rated by the respondents is Mostly Efficient and provides the required functionality with efficiency on used of system resources. According to M. Salleh et al. [21], efficiency is the ability of the system to deliver necessary performance that is comparative to the number of resources used, under specified circumstances.

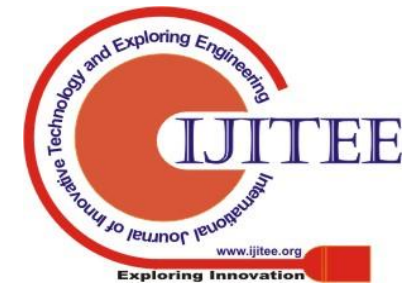


Table- IV (a): Qualitative Description per Maintainability Indicator

\begin{tabular}{|c|c|}
\hline Limits of Scale & Quality Description \\
\hline $4.21-5.0$ & Strongly Agree \\
\hline $3.21-4.20$ & Mostly Agree \\
\hline $2.61-3.20$ & Agree \\
\hline $1.81-2.60$ & Slightly Disagree \\
\hline $1.0-1.8$ & Strongly Disagree \\
\hline
\end{tabular}

Table- IV (b): Usability Indicators

\begin{tabular}{|l|c|c|c|}
\hline \multicolumn{1}{|c|}{ Questions } & $\mathbf{N}$ & Mean & Interpretation \\
\hline $\begin{array}{l}\text { 1. It is easily diagnosed for system } \\
\text { errors }\end{array}$ & 40 & 3 & Agree \\
\hline 2. The system is easily modified & 40 & 3.6 & Mostly Agree \\
\hline $\begin{array}{l}\text { 3. The system is easily ready for } \\
\text { testing }\end{array}$ & 40 & 3.5 & Mostly Agree \\
\hline \multicolumn{1}{|c|}{ OVERALL MEAN } & & $\mathbf{3 . 3 7}$ & Mostly Agree \\
\hline
\end{tabular}

Table 4.1 shows the system's maintainability an overall mean of 3.37 which implies that the developed prototype as rated by the respondents is Mostly Agree. As stated by Lincke and Lowe (2007), the maintainability characteristic permits closing on how far system can be maintained [22]. Therefore, the system conforms with the requirements of ISO 9126 concerning maintainability.

\section{CONCLUSION}

The developed prototype for high valued crops farming in Alfonso Lista, Ifugao is a holistic solution in revolutionizing traditional farming techniques which definitely reduces manual work, man power and provides efficiency on the use of farming resources. It facilitates the automatic irrigation, distribution and application of fertilizer, farm security and real-time monitoring of farm conditions like moisture, temperature, humidity and level of water and fertilizer. The implementation promotes sustainable agriculture with affordable and easy implementation for small scale farmers.

\section{ACKNOWLEDGMENT}

We would like to express appreciation to the Ifugao State University Research, Development, Extension and Training Service Unit and the Yaojiaxi Corporation - Alfonso Lista, Ifugao for the full support on this research endeavor in terms of shared insights and expertise, participation and funding.

\section{REFERENCES}

1. Philippine Statistic Authority (2018). Selected Statistic on Agriculture ISSN 2012-0362. pp. 1-2. Available: https://psa.gov.ph/sites/default/ files/Selected\%20Statistics\%20on\%20Agriculture\%202018.pdf.

2. N. Gondchawar and R. S. Kawitkar (2016, June). IoT based Smart Agriculture. Int. Journal of Advanced Research in Computer and Communication Engineering (IJARCC). Available: https://ijarcce.com/upload/2016/june-16/IJARCCE\%20188.pdf.

3. FAO (2017). The Future of Food and Agriculture: Trends and Challenges. pp. 11-16. Available: http://www.fao.org/3/a-i6583e.pdf.

4. S. Velten, J. Leventon, N. Jager and J. Newig (2015). What Is Sustainable Agriculture? A Systematic Review. Open access. ISSN 2071-1050. Available: https://www.mdpi.com.pdf.

5. V. N. Malavade and P. K. Akulwar (2016). Role of IoT in Agriculture. IOSR Journal of Computer Engineering (IOSR-JCE). Available: https://www.iosrjournals.org/iosr-jce/papers/Conf.16051/Volume-1/13. $\% 2056-57$. pdf?id=7557.

6. X. Shang, R. Zhang, X. Hu and Q. Zhou (2015). Design theory, modelling and the application for the Internet of Things service. Enterprise Information Systems. Vol. 10, No. 3, pp. 249-267. Available: https://www.researchgate.net/publication/282897523_Design_theory_m odelling_and_the_application_for_the_Internet_of_Things_service.
7. O. Vermesan and P. Friess (2014). Internet Of Things - From Research and Innovation to Market Deployment. River Publishers Series in Communication. ISBN: 978-8793102-95-8, pp. 20 -23. Available: http://www.internet-of-things-research.eu/pdf/IERC_Cluster_Book_201 4_Ch.3_SRIA_WEB.pdf.

8. Z. K. A. Mohammed and E. S. A. Ahmed (2017). Internet of Things Applications, Challenges and Related Future Technologies. World Scientific News, 67(2) (2017) pp. 126-148. Available: http://www.worldscientificnews.com/wp-content/uploads/2017/01/WSN -672-2017-126-148.pdf.

9. M. Stočes, J. Vaněk, J. Masner and J. Pavlík (2016). Internet of Things (IoT) in Agriculture - Selected Aspects. Agris on-line Papers in Economics and Informatics. Available: https://pdfs.semanticscholar.org /1580/5e20bc88088ee8b104639c491f6c72d5a135.pdf.

10. L. Zhang, I. Dabipi and L. Jr Brown (2018). Internet of Things Application for Agriculture. The Institute of Electrical and Electronics Engineers, Inc, pp. 509 - 513. Available: http://iranarze.ir/wp-content/uploads/2018/10/E9758-IranArze.pdf.

11. S. Veena, Mahesh K, Rajesh M and S. Salmon (2018). The Survey on Smart Agriculture Using IoT. International Journal of Innovative Research in Engineering \& Management (IJIREM) ISSN: 2350-0557. Volume-5 Issue-2. Available: https://www.ijirem.org/DOC/3_IREM523.pdf.

12. D. K. Sreekantha and A. M. Kavya (2017). Agricultural Crop Monitoring using IOT- A Study. 2017 11th International Conference on Intelligent Systems and Control (ISCO). Available: http://agri.ckcest.cn/ass/NK006-20170522001.pdf.

13. V. Bhuvaneswari and R. Porkodi (2014). The Internet of Things (IoT) Applications and Communication Enabling Technology Standards: An Overview. 2014 International Conference on Intelligent Computing Applications. Available: https://www.researchgate.net/publication 1286573266_The_Internet_of_Things_IoT_Applications_and_Commu nication_Enabling_Technology_Standards_An_Overview.pdf.

14. M. Elkhodr, S. Shahrestani and H. Cheung (2016). Internet of Things Applications: Current and Future Development. Information Science Reference, pp. 4-6, 15, 18. Available: https://www.researchgate.net /publication/316252878_Internet_of_things_applications_Current_and future_development.pdf.

15. A. Rghioui and A. Oumnad (2017). Internet of Things: Visions, Technologies, and Areas of Application Automation, Control and Intelligent Systems. Vol. 5, No. 6, 2017, pp. 83-91. Available: article.sciencepublishinggroup.com > 10.11648.j.acis.20170506.11

16. I. Mohanraj, K. Ashokumar and J. Naren (2016). Field Monitoring and Automation using IOT in Agriculture Domain. 6th Int. Conf. on Advances in Computing \& Communications (ICACC). Available: https://cyberleninka.org > article.

17. P. P. Jayaraman, A. Yavari, D. Georgakopoulos, A. Morshed and A Zaslavsky (2016). Internet of Things Platform for Smart Farming: Experiences and Lessons Learnt MDPI. pp. 2. Available: https://www.mdpi.com > pdf.

18. S. R. Prathibha, A. Hongal and M. P. Jyothi (2017). Iot Based Monitoring System In Smart Agriculture. 2017 International Conference on Recent Advances in Electronics and Communication Technology. Available: https://ieeexplore.ieee.org/document/8081906.

19. G. Rajakumar, S. Sankari, D. Shunmugapriya and S. P. U. Maheswari (2018). Iot Based Smart Agricultural Monitoring System. Asian Journal of Applied Science and Technology (AJAST); Vol 2, Issue 2, Pages 474-480. Available: http://ajast.net/data/uploads/4067.pdf.

20. G. G. Abatayo, C. Camiller, Y. L. Rapada, and R. Verecio (2018). Development of Human Resource Information System: 201 Files of Leyte Normal University. Journal of Computing and Innovation; (JCI). Vol 2 Issue 1. Available: lnu.edu.ph > lnujournals > index.php > jci > article > view > jci2118-3.

21. M. Salleh, M. Bahari and N. H. Zakaria (2017). An Overview of Software Functionality Service: A Systematic Literature Review. The 4th Information Systems Int. Conf. (ISIC). Available: https://www.researchgate.net/publication/322072677_An_Overview_of _Software_Functionality_Service_A_Systematic_Literature_Review.

22. R. Lincke and W. Lowe (2007). Compendium of Software Quality Standards and Metrics; Version 1.0, Pages 27-32. Available: https://pdfs.semanticscholar.org/7f56/8e27fd828d4badca3666e 589ef7b b58aa73b.pdf. 


\section{AUTHORS PROFILE}

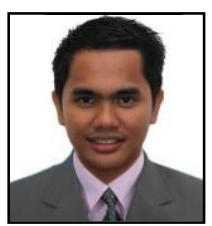

Domingo Junior P. Ngipol is an Information Technology (IT) Instructor at the Ifugao State University. He finished his bachelor's degree at Ifugao State University and earned his master's degree in Information Technology at the University of the Cordilleras, Baguio City, Philippines. He's currently taking up his Doctorate degree for Information Technology at the same university. He has ten years of professional experience as Information Technology instructor with expertise in computer hardware servicing, programming, computer networks and Internet of Things (IoT) Technologies. He has published one research article in the ACM Transactions as one of the leading journal and conference proceedings. He recently presented his second paper publication in The Second International Conference in Science, Engineering and Technology (ICoSET 2019) which was held in Pekanbaru, Indonesia. He is a member of the Computing Society of the Philippines which promotes researches in the area of computing sciences and engineering. He received scholarship from the Commission on Higher Education for his Master in Information Technology and Doctor of Information Technology Degree. His research interests include ICT applications, Internet of Things, Data mining, Game-based learning, Disaster Risk Management and Health Research. Currently, he is now in the development of IoT applications specifically on smart crop farming, poultry and home automation.

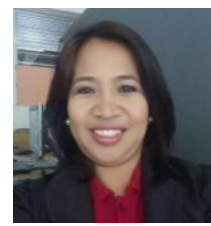

Thelma D. Palaoag is a faculty of the University of the Cordilleras, Baguio City, Philippines under the College of Information Technology and Computer Science. She earned her Master's and Doctorate Degree in Information Technology at the same school. She has more than 20 years of professional experience in machine learning, data mining, natural language processing and software engineering. She is currently handling subjects in graduate school programs which includes Master and Doctor of Information Technology. She has published more than 50 research articles in leading journals, conference proceedings including ACM Transactions and IEEE. She is a member of various organizations such as the Computing Society of the Philippines which promotes researches in the area of computing sciences and engineering. She received scholarship from the Commission on Higher Education for her Master in Information Technology and Doctor of Information Technology Degree. She has been awarded for best research paper in various conferences held in National and International venue. Her passion in research allows her to travel in many different countries. Her research interests include Natural Language Processing, Machine Learning, ICT applications, Data mining, Game-based learning, Software Engineering, Disaster Risk Management and Health Research. As she involves herself in IT research, she also engages herself in other research disciplines/areas such as social research on Health, Criminal Justice and other related areas. 